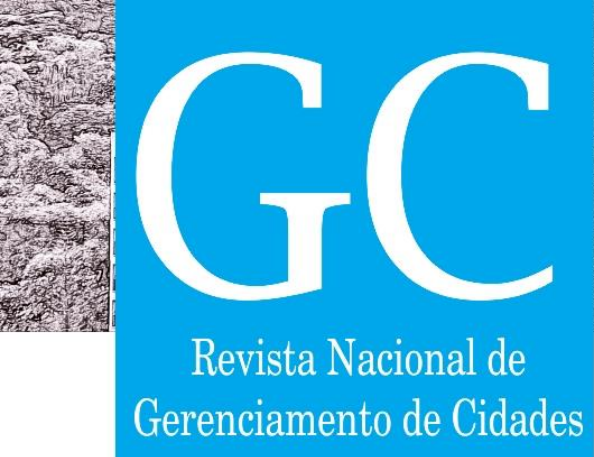

ISSN 2318-8472

\title{
Espaços públicos para brincar no contexto das cidades contemporâneas
}

Public space to play in the contemporary cities

Espacios públicos para jugar en el contexto de las ciudades contemporáneas

\author{
Larissa Leticia Andara Ramos \\ Professora Doutora, UVV, Brasil \\ larissa.ramos@uvv.br \\ Layra Marques Paixão \\ Arquiteta e urbanista, UVV, Brasil \\ layrapaixao@hotmail.com
}

\section{Luciana Aparecida Netto de Jesus \\ Professora Doutora, UFES, Brasil luciana.njesus@gmail.com \\ Karla Moreira Conde Professora Doutora, UFES, Brasil karlamconde@gmail.com}




\section{RESUMO}

Esta pesquisa tem como tema os espaços livres de uso público, com foco nos espaços para brincar e seu papel no desenvolvimento da infância, no enriquecimento sociocultural e na construção de cidades inclusivas, acolhedoras e que potencializem o ciclo completo da convivência urbana. Realiza, a partir de uma metodologia de avaliação préestabelecida, uma análise crítica dos espaços livres para práticas sociais, tendo como recorte a Regional Grande Aribiri, município de Vila Velha-ES, de modo a verificar como esses espaços estão incluindo as infâncias contemporâneas. Trata-se de uma pesquisa aplicada, de abordagem quanti-qualitativa, desenvolvida em quatro etapas metodológicas: contextualização; identificação e mapeamento; seleção e elaboração da metodologia de análise e avaliação dos espaços para brincar, por meio de indicadores organizados em quatro categorias: Proteção e Segurança; Conforto e Imagem; Acessos e Conexões; e Usos e Atividades. O artigo, além de apresentar a metodologia de avaliação proposta, discute a aplicação da mesma nas praças da Grande Aribiri, cujos resultados das análises auxiliam no melhor entendimento da interface entre as infâncias contemporâneas e a cidade, bem como indicam que as áreas mapeadas carecem de um novo olhar voltado a atender as reais necessidades das crianças.

PALAVRAS-CHAVE: Espaços livres de uso público. Espaços para brincar. Método de avaliação. Infâncias contemporâneas. Praças.

\section{ABSTRACT}

This research has as its theme the free spaces for public use, focusing on spaces for playing and their role in the development of childhood, in socio-cultural enrichment and in the construction of inclusive, welcoming cities that enhance the complete cycle of urban living. Performs, based on a pre-established assessment methodology, a critical analysis of free spaces for social practices, with the Regional Grande Aribiri, municipality of Vila Velha-ES, in order to verify how these spaces are including contemporary childhoods. It is an applied research, with a quantitative and qualitative approach, developed in four methodological stages: contextualization; identification and mapping; selection and elaboration of the methodology of analysis and evaluation of spaces to play, through indicators organized in four categories: Protection and Security; Comfort and Image; Accesses and Connections; and Uses and Activities. The article, in addition to presenting the proposed evaluation methodology, discusses the application in the squares of Grande Aribiri, whose analysis results help to better understand the interface between contemporary childhoods and the city, as well as indicate that the mapped areas need a new looking to meet the real needs of children.

KEYWORDS: Free spaces for public use. Play spaces. Evaluation method. Contemporary childhoods. Squares.

\section{RESUMEN}

Esta investigación tiene como tema los espacios libres para uso público, centrándose en los espacios para jugar y su papel en el desarrollo de la infancia, en el enriquecimiento sociocultural y en la construcción de ciudades inclusivas y acogedoras que mejoren el ciclo completo de la vida convivencia urbana. Realiza, con base en una metodología de evaluación preestablecida, un análisis crítico de los espacios libres para las prácticas sociales, teniendo como recorte el Regional Grande Aribiri, municipio de Vila Velha-ES, para verificar cómo estos espacios incluyen la infancia contemporânea. Es una investigación aplicada, con un enfoque cuantitativo y cualitativo, desarrollada en cuatro etapas metodológicas: Contextualización; identifcación y mapeo; selección y elaboración de la metodología de análisis y evaluación de los espacios para jugar, a través de indicadores organizados en cuatro categorías: Protección y Seguridad; Comodidad e imagen; Accesos y conexiones; y Usos y Actividades. El artículo, además de presentar la metodología de evaluación propuesta, discute la aplicación en las plazas de Grande Aribiri, cuyos resultados del análisis ayudan a comprender mejor la interfaz entre la infancia contemporánea y la ciudad, así como indican que las áreas mapeadas necesitan una nueva buscando satisfacer las necesidades reales un nuevo modo de ver y satisfacer las reales necesidades de los niños.

PALABRAS ClaVE: Espacios libres para uso público. Espacios de juego. Método de evaluación Infancia contemporánea. Plazas. 



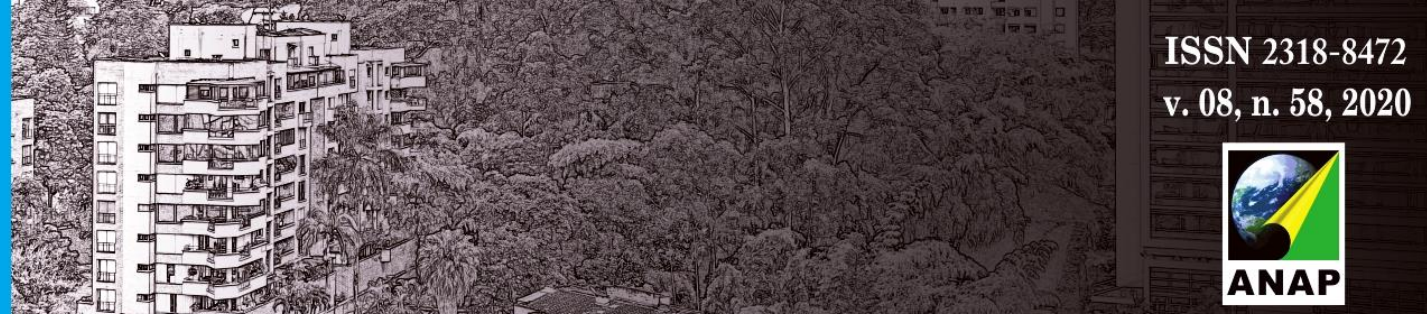

Revista Nacional de

Gerenciamento de Cidades

a "cultura do medo" também vem fortalecendo e tornando os espaços urbanos menos frequentados. Com isso, o brincar tem sido deslocado de fora para dentro. Diante desse cenário, na tentativa de manter as crianças afastadas dos problemas urbanos, as infâncias contemporâneas estão utilizando espaços privativos, segregados da vida social em comunidade, distantes dos perigos físicos e influenciadas por uma sociedade digitalizada e individualista. (BAUMAN, 2001). A infância livre está sendo sufocada pelas transformações da sociedade atual e sendo prejudicada pela ausência de oportunidades de se apropriar da cidade, esvaziando os espaços livres de uso público e perdendo sua representatividade

Somado a "cultura do medo", Sartori, Alvarez e Sommerhalder (2015) afirmam que existe uma tendência de padronização dos equipamentos e mobiliários infantis presentes nos espaços públicos, limitando os estímulos e as habilidades motoras, sensoriais e cognitivas das crianças, gerando também desinteresse e desafeição por esses espaços.

Dias (2018) afirma que as cidades possuem um longo caminho na promoção da atenção às crianças. Enfatiza que os planejadores devem considerar a requalificação desses espaços integrados ao tecido urbano para que estes possam ser vivenciados também pelas crianças. 0 planejamento do espaço público infantil deve ater às condições de apropriação e restrições específicas que valorizem as crianças, ressaltando que espaços seguros, acessíveis, atrativos e diversificados, influenciam na vivência urbana (COTRIM; BICHARA, 2013).

Ao contrário do que ocorre em muitas realidades, os projetos para espaços livres para brincar precisam instigar a iniciativa e a curiosidade da criança, sem adiantarem-se às suas formas de apropriação. Devem ainda dispor de equipamentos que garantam o desenvolvimento e a ludicidade, para que assim, seja possível resgatar os hábitos do brincar na cidade.

Nesse contexto, a presente pesquisa, a partir da aplicação de uma metodologia de avaliação préestabelecida, busca refletir sobre o brincar na cidade e compreender como os espaços livres de uso público estão incluindo as infâncias contemporâneas, tendo com recorte de análise as praças da Regional Grande Aribiri, munícipio de Vila Velha - ES. Visto a escassez de ferramentas direcionadas a análise, a discussão é realizada conforme parâmetros de avaliação desenvolvido por um grupo de pesquisa em parceria entre duas Universidades.

A identificação e a avaliação dos mesmos busca colaborar com estudos que enfatizam a qualidade dos espaços livres para brincar na cidade, bem como os efeitos da falta desses espaços sobre as comunidades. Permitem ainda retroalimentar o processo de projeto e evidenciar recomendações que possam influenciar em futuras intervenções para melhoria dos espaços avaliados e estimular a interface entre as infâncias contemporâneas e a cidade.

\section{MATERIAL E MÉTODO}

A cidade de Vila Velha faz parte da Região Metropolitana da Grande Vitória (RMGV) junto com outros seis municípios do estado do Espírito Santo: Cariacica, Fundão, Guarapari, Serra, Viana, Vitória e, por fim, Vila Velha. Através da Lei Municipal no 4707/2008 (VILA VELHA, 2008), é 


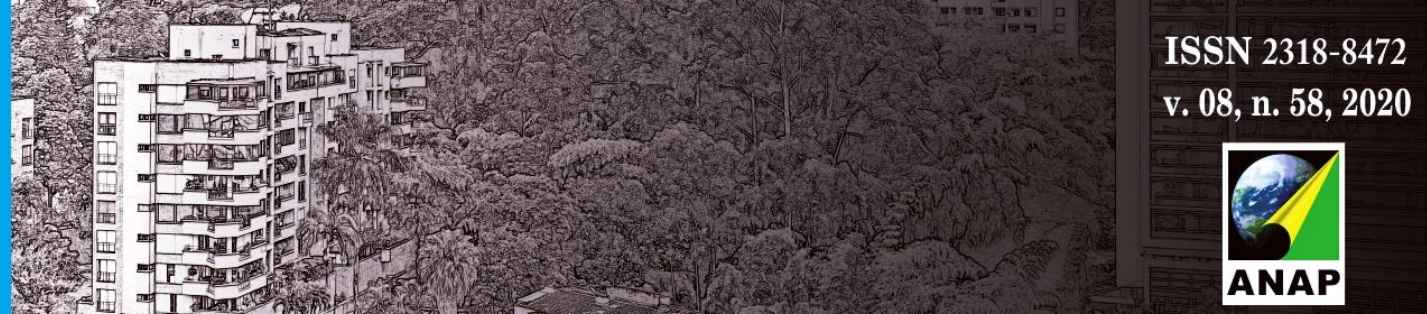

\section{Revista Nacional de}

Gerenciamento de Cidades

brincar na cidade, tendo como principais autores Cotrim e Bichara (2013); Sartori, Alvarez e Sommerhalder (2015); Medeiros (2016) e Dias (2018), bem como consultas às normas NBR 9050/2015 (ABNT, 2015) e NBR 16071/2012 (ABNT, 2012) para identificar condições que garantem a segurança e acessibilidade das crianças em playgrounds e em espaços públicos. Paralelamente a revisão bibliográfica, foram pesquisados exemplos de espaços públicos destinados a infâncias com padrões inclusivos e educativos.

Em seguida, os espaços foram identificados e mapeados com o auxílio do Sistema de Informações Geográficas (SIG), o ArcGIS (versão 10.5), a partir de dados geográficos disponibilizados pelos programas Google Earth e Google Maps, juntamente com visitas e levantamentos fotográficos em campo, confrontando as informações presentes com o Plano Diretor Municipal, de modo a gerar uma base cartográfica digital de dados.

Para análise dos dados espaciais, com base na distribuição e atendimento das praças da regional, utilizou-se a técnica de vetorização de feições espaciais ${ }^{1} \mathrm{e}$, posteriormente, a definição de uma área de abrangência considerando um raio de 400 metros $^{2}$, através da ferramenta espacial Buffer. A escolha pelo software ArcGIS resultou das possibilidades oferecidas pelo programa na inserção de atributos para tabulação e geração de dados georreferenciados.

Na sequência, foram desenvolvidos, pelo grupo de pesquisa "xxxxx", parâmetros de análises com base na ferramenta de Índice de Caminhabilidade (ITDP Brasil, 2018), considerando as adaptações necessárias para a aplicação em praças e ainda acrescendo indicadores específicos para o tema de estudo - espaços para brincar - visando garantir o conforto, a ludicidade e a segurança das crianças. As categorias de análise foram estabelecidas, de acordo com o Guia do Espaço Público ${ }^{3}$ (HEEMANN; SANTIAGO, 2015) que define temas considerados de maior relevância na avaliação destes espaços. Sendo assim, os parâmetros de análise propostos foram organizados em 04 (quatro) categorias: "Proteção e Segurança”, "Conforto e Imagem”, "Acessos e Conexões" e "Usos e Atividades", subdivididas em 7 atributos e 20 indicadores.

Vale destacar que o método avaliativo foi previamente testado e os dados organizados em categorias, atributos e indicadores para, assim, assegurar a aplicabilidade e posterior comparação de resultados. As categorias apresentam os principais parâmetros de referência para a avaliação. Os atributos são como "subcategorias", responsáveis pela maior organização e especificidade dos indicadores pertencentes. Já os indicadores são os responsáveis pela qualificação unitária do desempenho apresentado pelo objeto de estudo.

\footnotetext{
${ }^{1}$ Técnica de desenho digital sobre a imagem georreferenciada representada com uso do SIG.

${ }^{2}$ A definição do raio de 400 metros tem como referência as classificações de Berker et al (2006) que concebem as praças como espaços públicos de vizinhança, com raios de abrangência inferiores a $400 \mathrm{~m}$, correspondendo a um intervalo de tempo médio de cerca 5 minutos de caminhada, o que evita grandes deslocamentos e incentiva a presença de pessoas nos espaços.

${ }^{3}$ Documento baseado nos princípios e práticas da Project for Public Spaces, organização sem fins lucrativos de Nova York, fundada para difundir os trabalhos de Whyte (1980).
} 


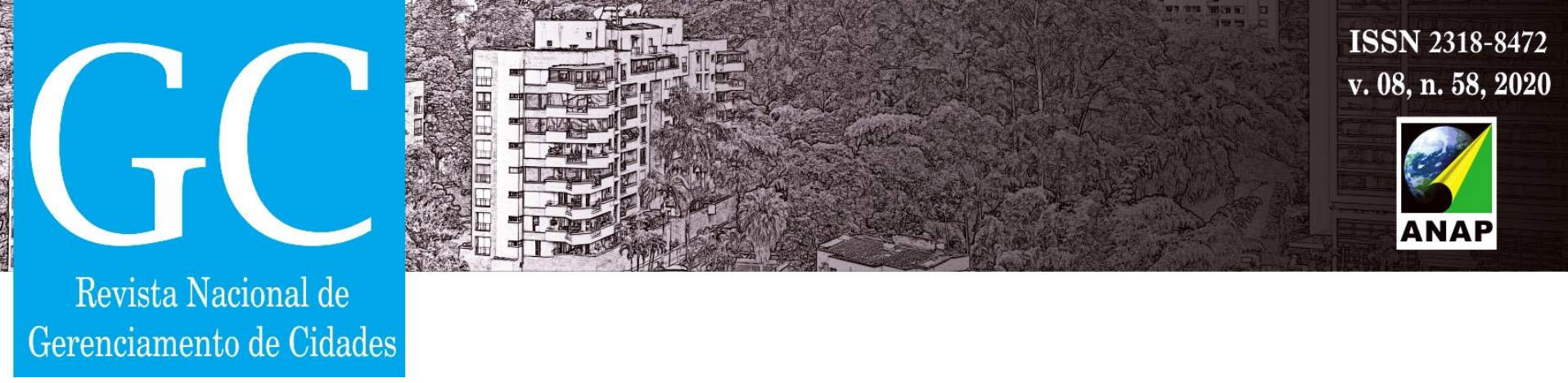

Quadro 1 - Indicadores e parâmetros de análise dos espaços.

\begin{tabular}{|c|c|c|c|c|c|c|}
\hline \multirow{2}{*}{ 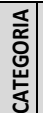 } & \multirow{2}{*}{ 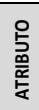 } & \multirow[b]{2}{*}{ INDICADOR } & \multicolumn{4}{|c|}{ PARÂMETRO DE AVALIAÇÃO } \\
\hline & & & $\begin{array}{l}\text { Pontuaç̧ão } 3 \\
\text { (Ótimo) }\end{array}$ & $\begin{array}{c}\text { Pontuação 2,0 a 2,9 } \\
\text { (Bom) }\end{array}$ & $\begin{array}{l}\text { Pontuação 1,0 a 1,9 } \\
\text { (Suficiente) }\end{array}$ & $\begin{array}{l}\text { Pontuação } 0 \text { a 0,9 } \\
\text { (Insuficiente) }\end{array}$ \\
\hline \multirow{10}{*}{ 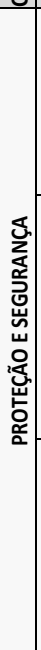 } & \multirow{3}{*}{ 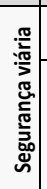 } & Travessias $^{(1)}$ & $\begin{array}{l}100 \% \text { das travessias } \\
\text { cumprem os requisitos }\end{array}$ & $\begin{array}{l}\geq 75 \% \text { das travessias } \\
\text { cumprem os requisitos }\end{array}$ & $\begin{array}{l}\geq 50 \% \text { das travessias } \\
\text { cumprem os requisitos }\end{array}$ & $\begin{array}{l}<50 \% \text { das travessias } \\
\text { cumprem os requisitos }\end{array}$ \\
\hline & & \multirow[b]{2}{*}{$\begin{array}{l}\text { Tipologia } \\
\text { da rua }\end{array}$} & \multirow[b]{2}{*}{$\begin{array}{l}\text { Vias exclusivas para } \\
\text { pedestres }\end{array}$} & $\begin{array}{c}\text { Vias compartilhas } \\
\text { Velocidade } \leq 20 \mathrm{~km} / \mathrm{h}\end{array}$ & $\begin{array}{l}\text { Vias compartilhadas } \\
\text { Velocidade } \leq 30 \mathrm{~km} / \mathrm{h}\end{array}$ & $\begin{array}{c}\text { Vias compartilhadas } \\
\text { Velocidade }>30 \mathrm{~km} / \mathrm{h}\end{array}$ \\
\hline & & & & $\begin{array}{c}\text { Vias com calçada } \\
\text { segregadas e } \\
\text { Velocidade } \leq 30 \mathrm{~km} / \mathrm{h}\end{array}$ & $\begin{array}{c}\text { Vias com calçadas } \\
\text { segregadas e } \\
\text { Velocidade } \leq 50 \mathrm{~km} / \mathrm{h}\end{array}$ & $\begin{array}{c}\text { Vias com calçadas } \\
\text { segregadas } \mathrm{e} \\
\text { Velocidade }>50 \mathrm{~km} / \mathrm{h}\end{array}$ \\
\hline & \multirow{3}{*}{ 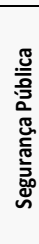 } & $\begin{array}{l}\text { Iluminação } \\
\text { pública (2) }\end{array}$ & $\begin{array}{c}\text { Resultado da } \\
\text { avaliação = } 100\end{array}$ & $\begin{array}{l}\text { Resultado da } \\
\text { avaliação = } 90\end{array}$ & $\begin{array}{l}\text { Resultado da } \\
\text { avaliação }=60\end{array}$ & $\begin{array}{l}\text { Resultado da } \\
\text { avaliação }<60\end{array}$ \\
\hline & & $\begin{array}{l}\text { Fluxo de } \\
\text { pedestres }^{(3)}\end{array}$ & $\begin{array}{l}\text { Nos turnos diurno e } \\
\text { noturno em todos os } \\
\text { dias da semana }\end{array}$ & $\begin{array}{c}\text { Em um dos turnos } \\
\text { (diurno ou noturno) em } \\
\text { todos os dias da } \\
\text { semana }\end{array}$ & $\begin{array}{l}\text { Em um dos turnos } \\
\text { (diurno ou noturno) } \\
\text { durante dias uteis/fins } \\
\text { de semana e feriados }\end{array}$ & $\begin{array}{l}\text { Ausência de pedestre } \\
\text { em diferentes turnos e } \\
\text { dias de semana }\end{array}$ \\
\hline & & $\begin{array}{l}\text { Câmeras de } \\
\text { segurança }\end{array}$ & $\begin{array}{c}\text { Presença de câmera de } \\
\text { segurança em toda a } \\
\text { praças e no playground }\end{array}$ & $\begin{array}{l}\text { Presença de câmera de } \\
\text { segurança somente em } \\
\text { um ponto da praça }\end{array}$ & $\begin{array}{l}\text { Presença de câmera de } \\
\text { segurança nas ruas } \\
\text { próxima a praça }\end{array}$ & $\begin{array}{c}\text { Ausência de câmera de } \\
\text { segurança }\end{array}$ \\
\hline & \multirow{4}{*}{ 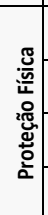 } & $\begin{array}{l}\text { Localização do } \\
\text { espaço infantil }\end{array}$ & Central e recintado & Central e não recintado & $\begin{array}{l}\text { Próximo as vias e } \\
\text { recintado }\end{array}$ & $\begin{array}{l}\text { Próximo as vias e não } \\
\text { recintado }\end{array}$ \\
\hline & & $\begin{array}{l}\text { Material piso } \\
\text { área infantil }\end{array}$ & Piso emborrachado & $\begin{array}{c}\text { Grama natural } \\
\text { ou grama sintética }\end{array}$ & Areia & $\begin{array}{l}\text { Piso asfáltico ou } \\
\text { intertravado }\end{array}$ \\
\hline & & $\begin{array}{c}\text { Materiais dos } \\
\text { brinquedos }\end{array}$ & $\begin{array}{c}\text { Plástico } \\
\text { Rotomoldado }\end{array}$ & $\begin{array}{c}\text { Madeira ou } \\
\text { emborrachado }\end{array}$ & Concreto & Metal \\
\hline & & $\begin{array}{c}\text { Conservação } \\
\text { brinquedos }\end{array}$ & Ótima & Boa & Suficiente & Insuficiente \\
\hline \multirow{5}{*}{ 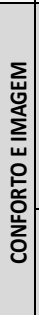 } & \multirow{4}{*}{ 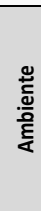 } & Coleta de lixo $^{(4)}$ & $\begin{array}{c}\text { Resultado da } \\
\text { avaliação = } 100\end{array}$ & $\begin{array}{c}\text { Resultado da } \\
\text { avaliação }=90\end{array}$ & $\begin{array}{c}\text { Resultado da } \\
\text { avaliação }=80\end{array}$ & $\begin{array}{c}\text { Resultado da } \\
\text { avaliação }<80\end{array}$ \\
\hline & & $\begin{array}{c}\text { Intensidade } \\
\text { sonora }\end{array}$ & $\leq 55 \mathrm{~dB}(\mathrm{~A})$ & $\leq 70 \mathrm{~dB}(\mathrm{~A})$ & $\leq 80 \mathrm{~dB}(\mathrm{~A})$ & $>80 \mathrm{~dB}(\mathrm{~A})$ \\
\hline & & Sombra & $\geq 75 \%$ da área & $\geq 50 \%$ da área & $\geq 25 \%$ da área & $<25 \%$ da área \\
\hline & & $\begin{array}{l}\text { Sombra no } \\
\text { playground }\end{array}$ & $\geq 75 \%$ da área & $\geq 50 \%$ da área & $\geq 25 \%$ da área & $<25 \%$ da área \\
\hline & 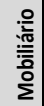 & Assentos (6) & $\begin{array}{c}>1 \text { assento de } 30,5 \mathrm{~cm} \\
\text { a cada } 11 \mathrm{~m}^{2} \text { de praça }\end{array}$ & $\begin{array}{l}<1 \text { assento de } 30,5 \mathrm{~cm} \\
\text { a cada } 11 \mathrm{~m}^{2} \text { de praça }\end{array}$ & $\begin{array}{l}\text { Presença de assentos } \\
\text { em locais permanência }\end{array}$ & Ausência de assentos \\
\hline \multirow{3}{*}{ 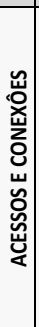 } & \multirow{3}{*}{ 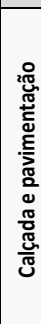 } & $\begin{array}{l}\text { Largura dos } \\
\text { percursos }\end{array}$ & $\begin{array}{c}\text { Largura mínima } \geq 2 \mathrm{~m} \mathrm{e} \\
\text { comporta o fluxo de } \\
\text { pedestres }\end{array}$ & $\begin{array}{l}\text { Largura mínima } \geq 1,5 \mathrm{~m} \\
\text { e comporta o fluxo de } \\
\text { pedestres }\end{array}$ & $\begin{array}{l}\text { Largura mínima } \geq 1,5 \mathrm{~m} \\
\text { e não comporta o fluxo } \\
\text { de pedestres }\end{array}$ & $\begin{array}{l}\text { Largura mínima } \\
<<1,5 \mathrm{~m}\end{array}$ \\
\hline & & $\begin{array}{l}\text { Pavimentação } \\
\text { da calçada no } \\
\text { entorno da } \\
\text { praça }\end{array}$ & $\begin{array}{l}\text { Todo o trecho é } \\
\text { pavimentado, não há } \\
\text { buracos ou desníveis }\end{array}$ & $\begin{array}{c}\text { Todo o trecho é } \\
\text { pavimentado } \leq 5 \\
\text { buracos ou desníveis a } \\
\text { cada } 100 \mathrm{~m} \text { de } \\
\text { extensão }\end{array}$ & $\begin{array}{c}\text { Todo o trecho é } \\
\text { pavimentado. } \leq 10 \\
\text { buracos ou desníveis a } \\
\text { cada } 100 \mathrm{~m} \text { de } \\
\text { extensão }\end{array}$ & $\begin{array}{c}\text { Não há pavimentação } \\
\text { em algum trecho ou > } \\
10 \text { buracos ou desníveis } \\
\text { a cada } 100 \mathrm{~m} \text { de } \\
\text { extensão }\end{array}$ \\
\hline & & $\begin{array}{l}\text { Pavimentação } \\
\text { da praça }\end{array}$ & $\begin{array}{l}\text { Todo a praça é } \\
\text { pavimentada, não há } \\
\text { buracos ou desníveis }\end{array}$ & $\begin{array}{c}\text { Todo a praça é } \\
\text { pavimentada } \leq 5 \\
\text { buracos ou desníveis a } \\
\text { cada } 200 \mathrm{~m}^{2}\end{array}$ & $\begin{array}{c}\text { Todo a praça é } \\
\text { pavimentada } \leq 10 \\
\text { buracos ou desníveis a } \\
\text { cada } 200 \mathrm{~m}^{2}\end{array}$ & $\begin{array}{c}\text { Não há pavimentação } \\
\text { em algum trecho ou > } \\
10 \text { buracos ou desníveis } \\
\text { a cada } 200 \mathrm{~m}^{2}\end{array}$ \\
\hline \multirow{3}{*}{ 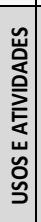 } & \multirow{3}{*}{ 䓂 } & $\begin{array}{l}\text { Estímulos } \\
\text { motores (7) }\end{array}$ & $\geq 5$ equipamentos & $\geq 4$ equipamentos & $\geq 3$ equipamentos & $<2$ equipamentos \\
\hline & & $\begin{array}{l}\text { Estímulos } \\
\text { sensórias/ } \\
\text { lúdicos (8) }\end{array}$ & $\begin{array}{c}\geq 3 \text { possibilidades de } \\
\text { estímulos } \\
\text { sensórias/lúdicos }\end{array}$ & $\begin{array}{c}\geq 3 \text { possibilidades de } \\
\text { estímulos } \\
\text { sensórias/lúdicos }\end{array}$ & $\begin{array}{l}\geq 1 \text { possibilidades de } \\
\text { estímulos } \\
\text { sensórias/lúdicos }\end{array}$ & $\begin{array}{c}\text { Nenhuma possibilidade } \\
\text { de estímulos } \\
\text { sensórias/lúdicos }\end{array}$ \\
\hline & & $\begin{array}{c}\text { Brincadeiras de } \\
\text { regras }\end{array}$ & $\begin{array}{l}\text { Presença de quadra e } \\
\text { espaços livres para } \\
\text { brincadeiras de regras }\end{array}$ & Presença de quadra & $\begin{array}{l}\text { Presença de espaços } \\
\text { livres que estimulem } \\
\text { brincadeiras de regras }\end{array}$ & $\begin{array}{l}\text { Ausência de quadra e } \\
\text { espaços livres para } \\
\text { brincadeiras de regras }\end{array}$ \\
\hline \multicolumn{7}{|c|}{$\begin{array}{l}\text { (1) São requisitos de qualidade: presença adequada de faixa de pedestre, rebaixo da calçada, piso podotátil e sinalização viária. } \\
\text { (2) Cálculo foi obtido através da soma das notas: }+20 \text { quando há pontos de iluminação voltados para a rua; }+40 \text { quando há pontos } \\
\text { de iluminação na praça na escala do pedestre; }+40 \text { quando há pontos de iluminação nas travessias; }-10 \text { quando há obstruções de } \\
\text { iluminação devido a presença de árvores ou lâmpadas quebradas. } \\
\text { (3) O período de contagem para o fluxo de pessoas foi de } 15 \text { minutos. Média entre os horários de pico: } 8 \text { h, } 13 \mathrm{~h} \text { e } 19 \mathrm{~h} \text {, durante os } \\
\text { meses de novembro } 2018 \text { a março de } 2019 \text {. } \\
\text { (4) O cálculo se dá pela subtração das notas a partir da nota }+100 \text { (valor de referência para um ambiente limpo e adequado ao } \\
\text { pedestre). -10 presenças de saco de lixos; }-20 \text { presença de detritos; }-40 \text { presença de lixo critico; e -30 presença de entulhos. } \\
\text { (5) Segundo a organização Mundial da Saúde, um ambiente urbano é adequado quando o nível de intensidade sonora é inferior a } \\
55 \text { dB(A). Níveis acima de } 80 \text { dB(A) podem contribuir para desencadear comportamentos agressivos (ITDP Brasil, 2018). } \\
\text { (6) Referência o "City Planning Website Survey" ( NOVA YORK, 2019), considerando a densidade habitacional de Vila Velha. } \\
\text { (7) Observa-se os brinquedos/equipamentos permitem atividades motoras: subir/escalar; pular/correr, ecorregar, balançar e girar. } \\
\text { (8) Observa-se os brinquedos/equipamentos estimulam sentidos: Tátil, auditivo, olfativo e visual. }\end{array}$} \\
\hline
\end{tabular}

Fonte: Elaborado pelos autores, 2019. 



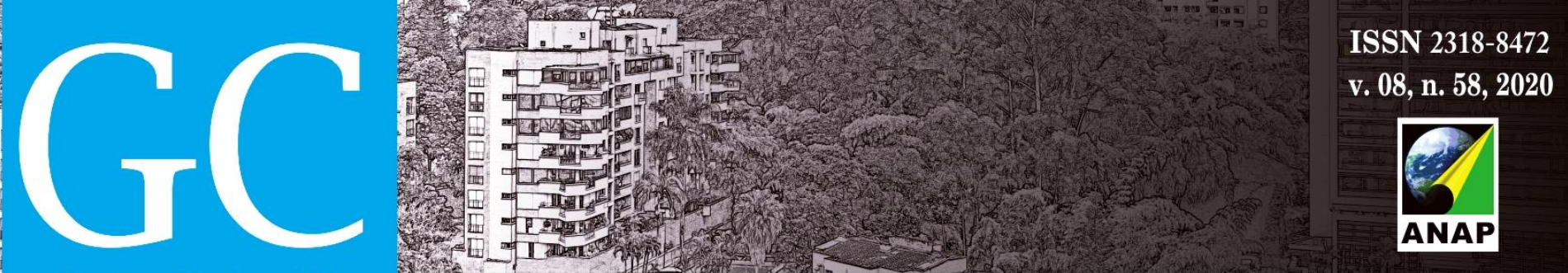

\section{Revista Nacional de} Gerenciamento de Cidades

acidentes, tais como as travessias e a tipologia das vias; bem como a segurança pública a partir da análise do fluxo de pedestre, da presença de câmeras de vigilância e da iluminação pública. Além disso, aspectos ligados à proteção física - localização e piso do espaço infantil, material e estado de conservação dos brinquedos - também foram avaliados.

Para garantir a proteção física das crianças, os espaços para brincar precisam estar localizados em uma região central e protegida da praça. Os materiais de revestimento do piso devem ser adequados para evitar acidentes e garantir a acessibilidade. Sendo assim, os resultados das análises referentes à categoria "Proteção e Segurança" apontam (conforme figura 03) que, das 09 (nove) praças avaliadas da Grande Aribiri, 4 (quatro) foram pontuadas como "suficiente" (evidenciadas pela cor amarela) e 05 (cinco) "insuficiente" (evidenciadas pela cor vermelha). Nenhuma das praças obteve resultado "ótimo" ou "bom" em relação à categoria "Proteção e Segurança", demonstrando, assim, a necessidade de intervenção no que tange a proteção física e a segurança viária e pública dos espaços analisados.

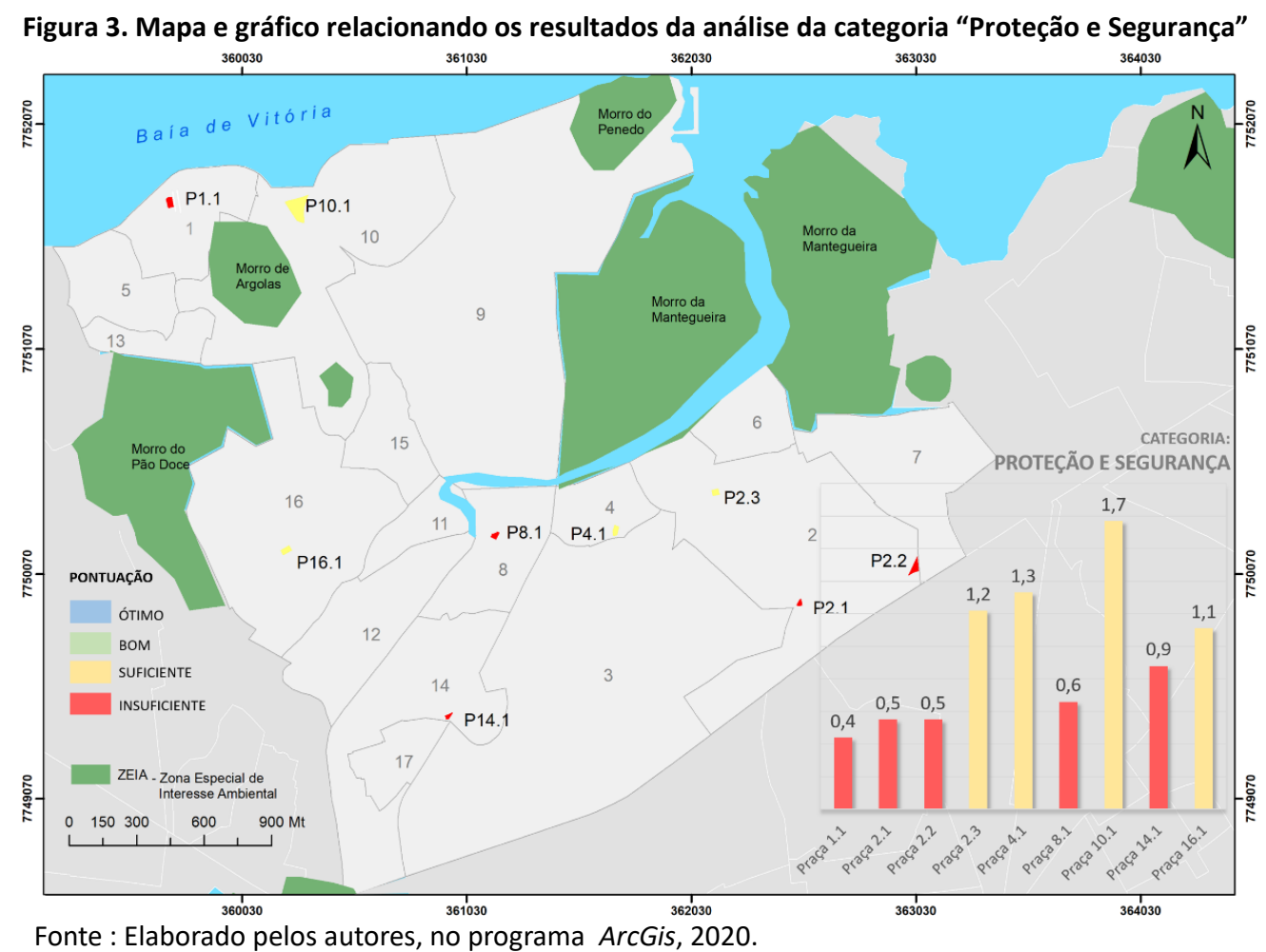

A praça de Paul (praça P 10.1 - figuras 4 e 5) foi a melhor qualificada, com as maiores notas em relação fluxo de pessoas, além de ser monitorada por câmeras de segurança, possuir travessias sinalizadas, boa iluminação pública e ótimo estado de conservação dos espaços para brincar. 


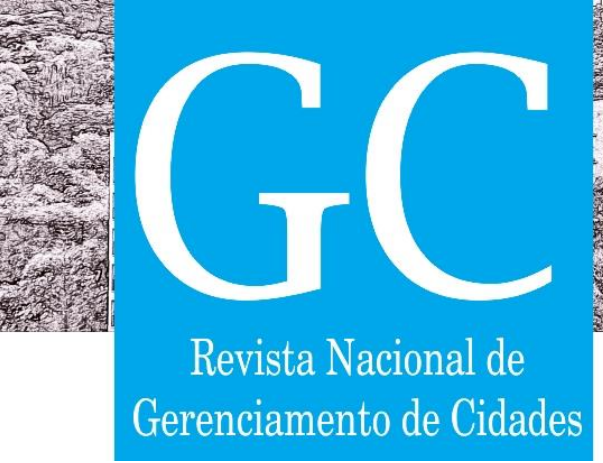

\section{Análise do "Acessos e Conexões" das praças da Grande Aribiri}

A categoria "Acessos e Conexões" compreende os atributos mobilidade, calçada e pavimentação, considerando dimensões, revestimentos e superfícies adequadas a todas as pessoas, em especial, ao público infantil, e em atendimento a NBR 9050/2015 (ABNT, 2015). A maioria das praças obtiveram resultados "suficientes" (evidenciado em amarelo na figura 9). Apenas a praça do bairro Paul (Praça P10.1) atingiu nota "boa" (evidenciada em verde).

Figura 9. Mapa e gráfico relacionando os resultados da análise da categoria "Acessos e Conexões"

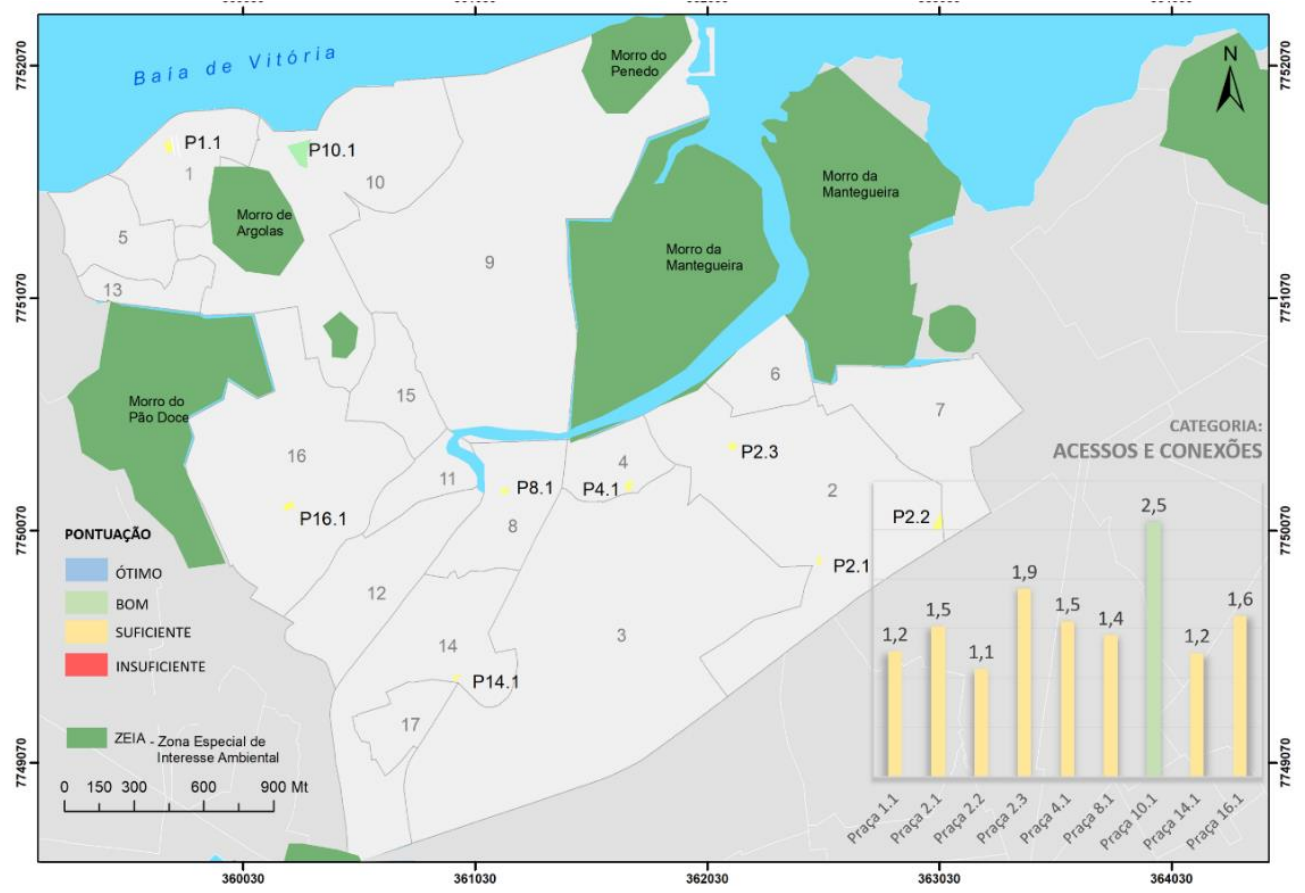

Fonte: Elaborado pelos autores, no programa ArcGis, 2020.

A praça Conjunto Barcelos, localizada no bairro Aribiri (Praça P2.2 de acordo com a figura 9), alcançou a pior avaliação tendo em vista a pavimentação da praça e espaço para brincar bem como o dimensionamento inadequado das calçadas e percursos internos existentes na praça, inferiores as $120 \mathrm{~cm}$. Nas figuras 10 e 11 , nota-se a situação da praça Conjunto Barcelos, classificada como "suficiente" para a categoria de "acessos e conexões". 


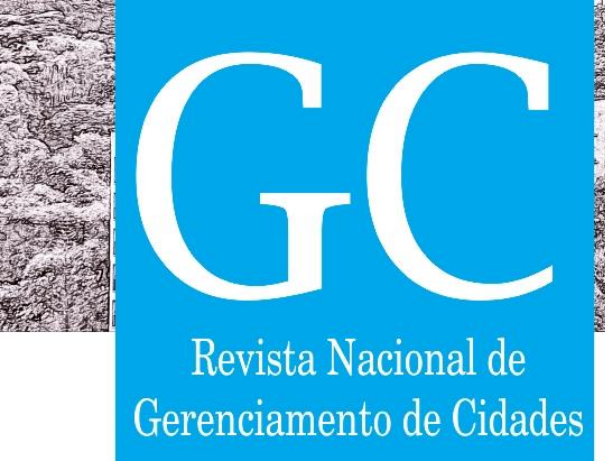

Figura 10. Praça Conjunto Barcelos (Praça 2.2)

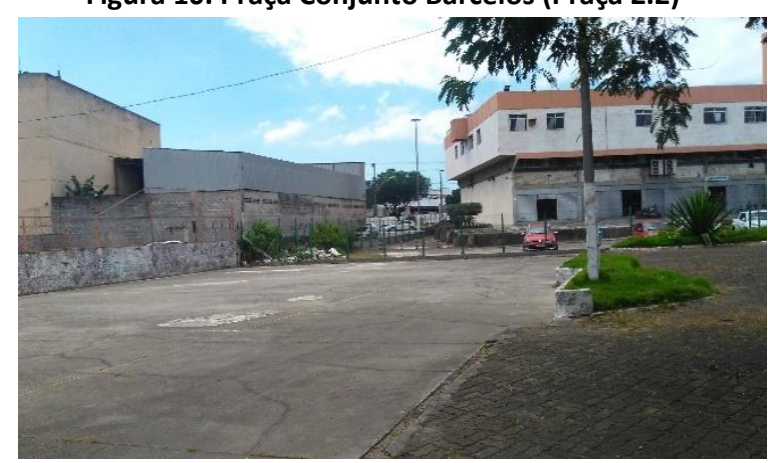

Fonte: acervo dos autores, 2019.
Figura 11. Praça Conjunto Barcelos (Praça 2.2)

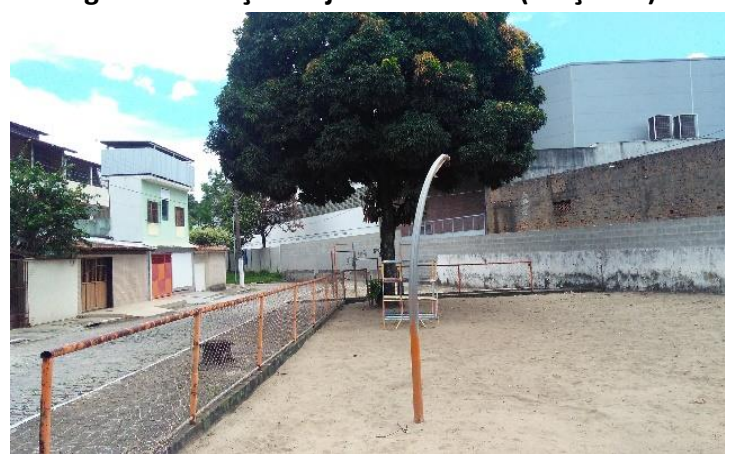

Fonte: acervo dos autores, 2019.

\section{Análise do" Usos e Atividades" das praças da Grande Aribiri}

A última categoria avaliada foi “Usos e Atividades”. É nela que os diferentes estímulos motores, sensoriais/lúdicos voltados às crianças foram verificados, tais como: a presença de brinquedos/equipamentos que permitem subir, escalar, pular, correr, escorregar, balançar e girar; bem como aqueles que visam estimular aspectos sensoriais - incentivando os sentidos táteis, auditivos, olfativos e visuais. A figura 12 ilustra o resultado da avaliação.

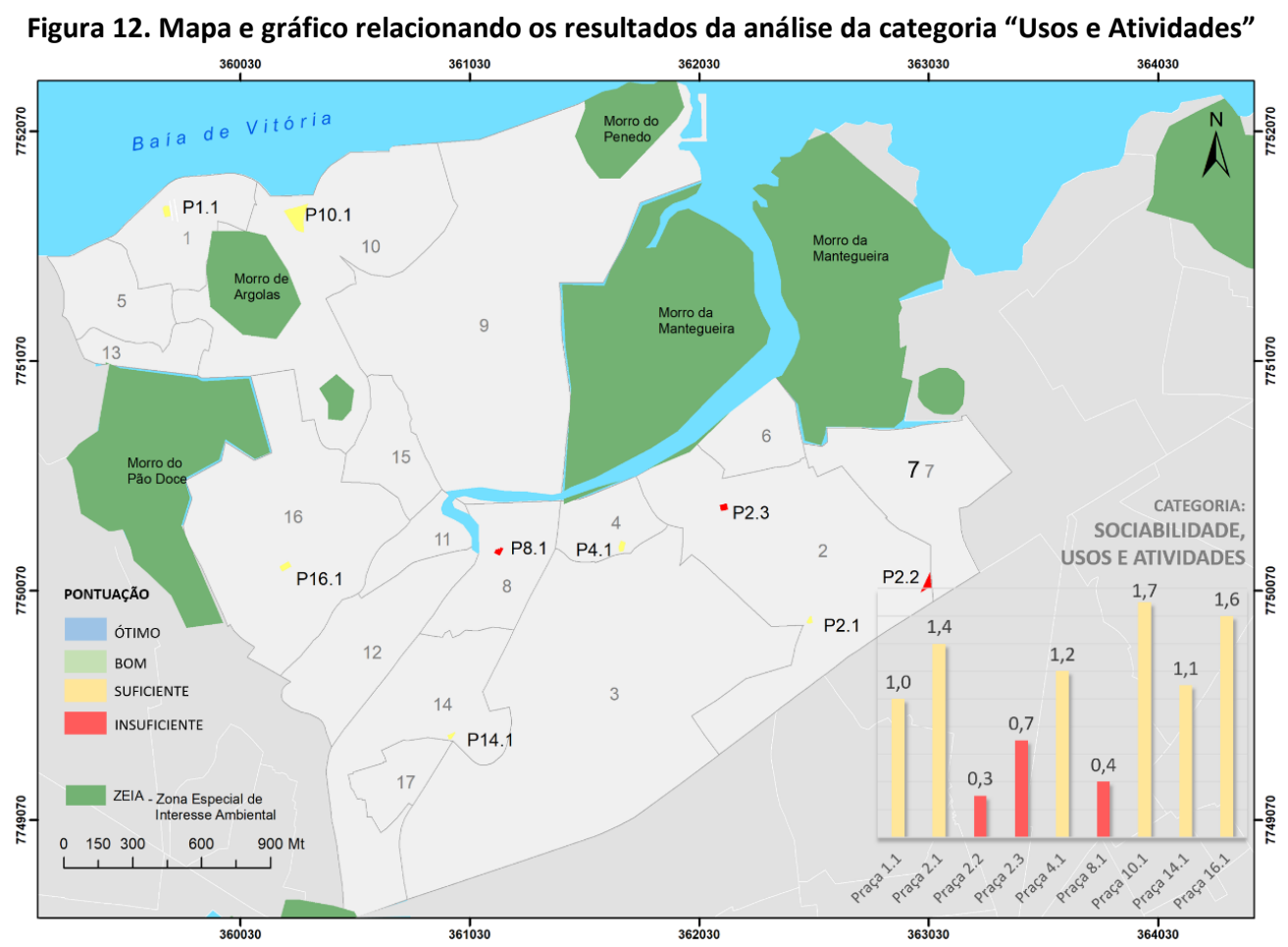

Fonte: Elaborado pelos autores, no programa ArcGis, 2020. 


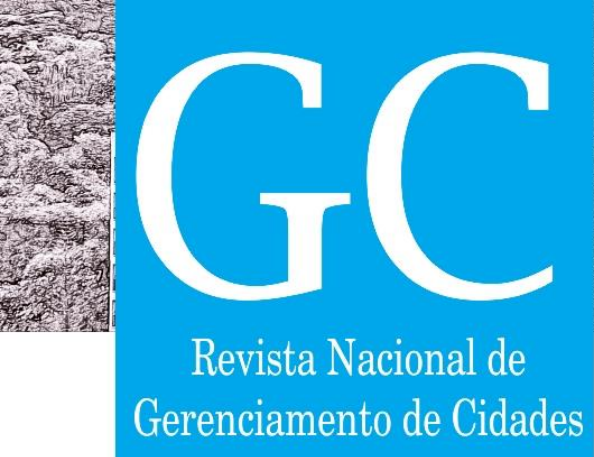

Observando os resultados, 6 (seis) praças receberam notas "suficiente" (evidenciadas em amarelo) e 3 (três) "insuficiente" (evidenciadas em vermelho). As piores praças avaliadas nesta categoria foram as praças Conjunto Barcelos (P2.2) e a do bairro llha da Conceição (P 8.1), por não possuírem equipamentos que auxiliam nos estímulos motores, sensoriais e lúdicos das crianças (Figuras 14 e 15).

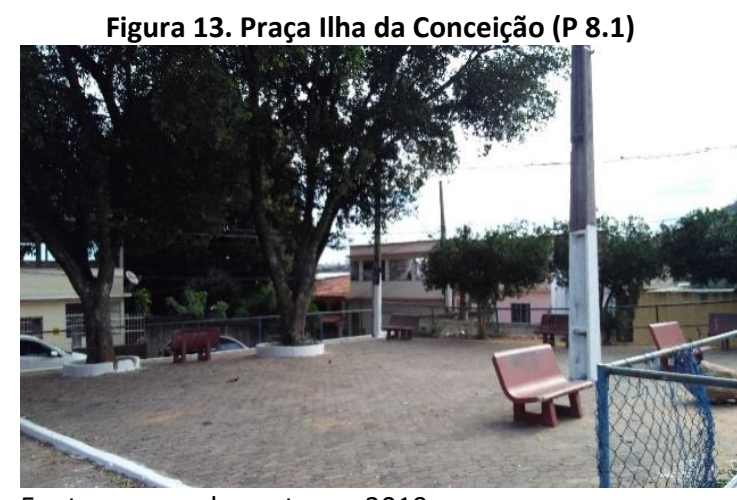

Fonte: acervo dos autores, 2019.
Figura 14. Praça Conjunto Barcelos (P2.2)

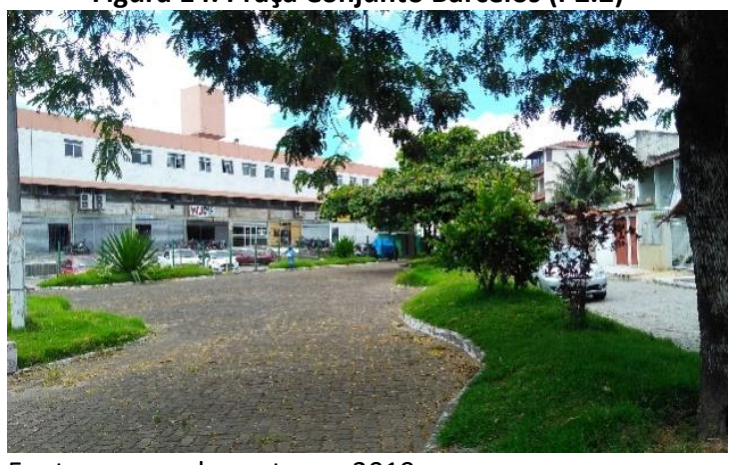

Fonte: acervo dos autores, 2019.

\section{Considerações sobre os resultados da aplicação da metodologia de avaliação nas praças}

Para ilustrar o resultado das análises das praças, foram utilizados gráficos do tipo radar (figura 15) que possibilitam a interpretação de dados, atribuindo os indicadores de determinada categoria, em uma escala que varia de 0 a 3, correspondendo à pontuação atribuída. Nos gráficos do tipo radar, quanto mais próxima da extremidade do polígono, maior o valor atribuído e quanto mais próximo do centro, menor o valor. 


